\title{
High Speed Gas Sampling System for Engine Cylinder Emission Analyses
}

\author{
Nuri Yucel, Salih Karaaslan, Ender Hepkaya, and Nureddin Dinler
}

\begin{abstract}
In this study, high speed gas sampling system was used to collect gas samples in the engine cylinder. $C_{1}-C_{5}$ based HC components behaviuor in the engine cylinder were investigated experimentally during the flame period. Model GSD-10 fast response gas sampling system was used to sample gas in the cylinder. The high speed gas sampling valve mounted on the engine cylinder was connected to the gas chromatograph instrument directly, and samplings were continuously gathered at the intended crank shaft angle ranges. The electro-magnetic valve lift time was controlled by setting a time-lag from the TDC reference point of the engine crank angle. Crank pulses were provided by crank pulse generator. The generator consists of a slit disc mounted on the engine shaft and a photo-electric pick-up. It was designed to generate the crank pulse (360 pulses/rev) and the reference pulse (1 pulse/rev). In cylinder gas samples were taken for 10-15 degree intervals after the ignition. Samples taken during the flame period were approximately 60 degrees of crank angle after the spark plug ignited. In this study, Agilent 7890A Gas Chromatography (GC) system was employed to analyze $\mathrm{C}_{1}-\mathrm{C}_{5} \mathrm{HC}$ component of the sampled gas from the engine cylinder. GC-FID (Flame Ionization Detector) analysis method was utilized to investigate hydrocarbon components. Response time of hydrocarbon components were listed. HC components variation with respect to crank angle were plotted and interpreted.
\end{abstract}

Index Terms-Gas sampling system, in cylinder engine emissions, he components.

\section{INTRODUCTION}

The use of a fast flame-ionization detector (FID) system for measuring hydrocarbon $(\mathrm{HC})$ levels in spark ignition engine cylinder was described in the study of N. Ladommatos [1]. The system in that study [1] was used to measure the hydrocarbon levels in each engine cycle. Results were obtained that in-cylinder excursion of air-fuel ratio after sudden throttle opening and the amount of trapped combustion residuals in the cylinder during low-load low-speed running, and the effect of residuals on combustion [1].

Exhaust $\mathrm{HC}$ emissions from spark ignition engines play an important role in photochemical reactions. In the study of I. Shizuo and L. Tamotsu, the source of unburned HCs from engines were considered as quenching in the crevices of combustion chamber as well as oil layer and deposits on the combustion chamber wall [2]. The behavior of unburned HCs

Manuscript received November 25, 2012; revised January 29, 2013. This work was supported by the Scientific Technological Research Council of Turkey under Grant of Support Programme for Scientific and Technological Research Project (Project Code: 109M420).

The authors are with Faculty of Engineering Mechanical Engineering, Department Ankara Turkiye, Gazi University, Turkey (e-mail: nuyucel@gazi.edu.tr; karaaslansalih@gazi.edu.tr; ndinler@gazi.edu.tr). on the combustion chamber wall was investigated with using a high speed gas sampling technique during the expansion and exhaust processes [2]. A. C. Alkidas [3] reviewed the studies investigating sources as combustion chamber crevices and reducing techniques of $\mathrm{HC}$ emissions. The researcher concluded that combustion and flow field inside the combustion chamber effect the burned gas concentration in the crevices strongly [3]. Effect of fuel composition in spark ignition engine is an important parameter to reduce hydrocarbon emissions. H. Zuohua et al. [4] used a single cylinder engine which was operated on hexane-gasoline and xylene-gasoline blends. Total hydrocarbon emissions have been measured by FID. It was shown that Henry's constant, diffusion coefficient and distillation temperature of fuel components dominate the mass of in-cylinder unburned hydrocarbons were influenced by the fuel. The compositions of the fuel greatly influence the engine out HC emissions [4]. N. A. Henein and M. K. Tagomori [5] presented the source of tailpipe $\mathrm{HC}$ emissions during cold start. They used port injected gasoline engines. They investigated the parameters which influences tailpipe $\mathrm{HC}$ emissions on cycle basis. Fast response flame ionization detector (FFID) measurements of engine out $\mathrm{HC}$ emissions were given. At the end of the study, the approaches for reducing cold-start operation tailpipe and engine-out $\mathrm{HC}$ emissions were discussed [5]. In another experimental study, effects of very lean fuel/air ratio conditions on $\mathrm{HC}$ emissions were investigated [6]. FFID used to measure high concentrations of $\mathrm{HC}$ emissions for two test cycles. For the same burned mass fraction, the cycles have different IMEP and different HC emissions due to partial combustion and varying degrees of post flame oxidation inside the cylinder [6]. In a study of B.M. Broderick and I.S. Marnane [7], hydrocarbon concentrations of ambient, fuel and hourly road were measured on a heavy traffic junction for more than 45 days. They concluded that the $\mathrm{HC}$ concentration of ambient air (suspected unburned fuel components) and fuel's relative $\mathrm{HC}$ concentrations were in good agreement, when the major partial oxidation products were ignored [7]. C. S. McEnally et al. [8] investigated $\mathrm{CH}_{4}$ to $\mathrm{C}_{12} \mathrm{H}_{26}$ alkanes, volume fraction of soot, major components and temperature in methane/air non-premixed flames. The fuel used in the study was separately doped with $5000 \mathrm{ppm}$ of five heptanes isomers [8]. W. Yang [9] used Sokken model GSD-10 type unit in order to investigate the hydrocarbon oxidation studies on Homogeneous Charge Compression Ignition (HCCI) engine. Also, he developed a kinetic model to predict pressure, temperature and heat release rate for the same engine. The results of experimental and model studies were in good agreement.

In our study, Ricardo research engine was used with the 
in-line sampling system with $\mathrm{GC}$ analyzer. $\mathrm{C}_{1}-\mathrm{C}_{5}$ based $\mathrm{HC}$ components in the cylinder were collected via the high speed gas sampling system. Then the instantaneous samples were analyzed by using GC-FID technology.

\section{EXPERIMENTAL SETUP}

All experiments were carried out on a single cylinder Ricardo E6 research engine which has variable compression ratio. The engine was coupled to a DC dynamometer with DV-300 control module to provide free motoring and firing capabilities. The control module is wired to a dynamometer with a rated maximum speed of $3000 \mathrm{rpm}$. While engine runs, the dynamometer could be maintained the speed within \pm 5 rpm of the preset conditions. A flywheel is connected to the crankshaft in order to reduce cyclic variation and speed fluctuations caused by the intermittent combustion events. The specifications of Ricardo E6 research engine are listed on Table I.

TABLE I: RICARDO E6 ENGINE SPECIFICATIONS
\begin{tabular}{|l|r|}
\hline Cylinder Diameter & $76.2 \mathrm{~mm}$ \\
\hline Stroke & $111.1 \mathrm{~mm}$ \\
\hline Displacement Volume & 0.5071 \\
\hline Max. Rev. number & $3000 \mathrm{rpm}$ \\
\hline Maximum Power & $9.4 \mathrm{~kW}$ \\
\hline Max. Cylinder Pressure & $150 \mathrm{bar}$ \\
\hline Fuel & Gasoline \\
\hline Static Ignition & $25^{\circ}$ BTDC \\
\hline Compression Ratio & variable \\
\hline
\end{tabular}

Engine in-cylinder gases were extracted at the prespecified crank angle ranges during combustion period by using high speed gas sampling system. Model GSD-10 gas sampling system basically consist of two main units: a high speed electro-magnetic gas sampling needle valve and a high speed magnetic exciter which is designed to provide the exciting current to the needle valve. In addition to that, the auxiliary instrumentations are supplied with the main unit. Those are:

- A sampling valve controller which enables the sampling valve to operate at the desired timing.

- A crank pulse generator which provides the crank angle information to the controller.

- A valve motion detector which monitors valve lifts wave-forms or performances of the sampling valve.

Accordingly, the high speed gas sampling system, model GSD-10, is completed with;

1. Electro-magnetic gas sampling needle valve,

2. High speed magnetic exciter,

3. Sampling valve controller,

4. Crank pulse generator with slit disc,

5. Valve motion detector,

6. Rack.

The sampling valve controller provides the control signal to the exciter. The controller can amplify and shape pulse signals from the photo-electric pick-up mounted on engine shaft. In the case of four cycle engine, this unit has an additional function which TDC reference pulse can be divided into half. The lift time of the sampling valve is controlled by setting a time-lag from the reference TDC point.
The generator, which is consisted of a slit disc and a photo-electric pick-up, is designed to generate the crank pulse (360 pulses/rev) and the reference pulse ( 1 pulse/rev). These pulses are provided to the valve controller, and then amplified and shaped. The detector detects the lift of the sampling valve and generates voltage output. The schematic layout of the experimental setup is shown in Fig. 1.

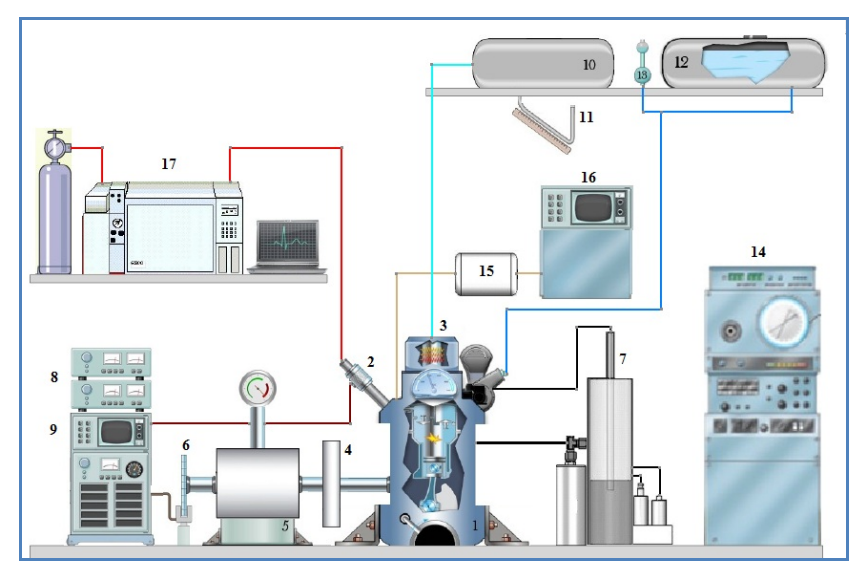

\begin{tabular}{|l|l|}
\hline Number & Device \\
\hline $\mathbf{1}$ & Ricardo E6 Single Cylinder Research Engine \\
\hline $\mathbf{2}$ & Electromagnetic Sampling Valve \\
\hline $\mathbf{3}$ & Intake air conditioner \\
\hline $\mathbf{4}$ & Flywheel \\
\hline $\mathbf{5}$ & Dynamometer \\
\hline $\mathbf{6}$ & Slit Disk/Photo Electric Reader \\
\hline $\mathbf{7}$ & Cooling Water Tower + Water Pump + Heat Exchanger \\
\hline $\mathbf{8}$ & 2 x Oscilloscope \\
\hline $\mathbf{9}$ & High-Speed Gas Sampling Device \\
\hline $\mathbf{1 0}$ & Orifice and Air Tank \\
\hline $\mathbf{1 1}$ & Inclined Manometer \\
\hline $\mathbf{1 2}$ & Fuel Tank \\
\hline $\mathbf{1 3}$ & Glass Measuring Tube \\
\hline $\mathbf{1 4}$ & Ricardo E6 Engine Control Panel \\
\hline $\mathbf{1 5}$ & Exhaust Silencer \\
\hline $\mathbf{1 6}$ & Exhaust Gas Analyzer \\
\hline $\mathbf{1 7}$ & Gas Chromatography Equipment + Data Logger + Gas Tubes \\
\hline
\end{tabular}

Fig. 1. Schematic layout of the experimental installation.

In-cylinder gas samples collected by an electromagnetic sampling valve located at opposite of the spark plug. The sampling unit is a Sokken model GSD-10 type unit. Inside the valve, on the valve rod one side it has electromagnet part, on the other side valve rod is mounted in to the seat of valve body using spring. When the electromagnet is triggered, it pulls the needle from the seat so that sampling gas flow through the valve into the sampling line. Sampling start and duration of valve is controlled by a pulse generator. Shorten the sampling duration time increases the resolution of the species evolution measurement. The sampling unit's minimum sampling time is $3 \mathrm{~ms}$. However, at $1200 \mathrm{rpm}$ engine speed the sampling time is $2.08 \mathrm{~ms}$ or $15 \mathrm{CA}$. This is obtained by adjusting the spring force using control panel. The opening duration is monitored using a LED (Light Emitting Diode) source and receiver pair. When the valve is triggered the needle lifts breaking the LED beam. The voltage from the LED receiver is monitored on an oscilloscope. Gas composition is obtained via a fast sampling 
valve from $340 \mathrm{CA}$ to $390 \mathrm{CA}$. The engine is operated at an engine speed of $900 \mathrm{rpm}$. Static spark ignition aligned $20 \mathrm{CA}$ before TDC. Dynamic spark ignition occurred around 315-325 CA for all tests. To ensure stable operation of the high speed gas sampling valve, peak hold durations and exciting voltages are traced by using two oscilloscopes. Due to high pressure and temperature in the combustion chamber, there is a probability of unstable valve actuation after spark ignition that results the sampling duration unstable. Sampling interval with respect to cycle, sampling duration (CA) holds and reverses the timing of the high speed gas sampling system which is set desired values not to exceed minimum valve opening time $2 \mathrm{~ms}$. To analyze the hydrocarbons, Agilent Gas Chromatogram system is used. The GC-FID specifications are represented in Table II.

TABLE II : GC-FID SPECIFICATIONS

\begin{tabular}{|l|l|}
\hline Device & Agilent 7890A Gas Chromatography \\
\hline Detectors & FID \\
\hline Method & Automatic injection (continuous line connection) \\
\hline $\begin{array}{l}\text { Oven } \\
\text { Temperature }\end{array}$ & $30^{\circ} \mathrm{C}$ (Before analysis, Cold case) \\
\hline Columns & Hayesep-D-5 30m, D $=0.320 \mathrm{~mm}$, Film $=0.25 \mu \mathrm{m}$ \\
\hline Carrier Gas & Helium @ 18 PSI Dry Air \\
\hline $\begin{array}{l}\text { Temperature } \\
\text { Program }\end{array}$ & $\begin{array}{l}\text { Starting from } 30^{\circ} \mathrm{C} \text { and wait } 8 \text { minutes. Then temperature } \\
\text { rising to } 60^{\circ} \mathrm{C} \text { with using } 40^{\circ} \mathrm{C} / \text { min heating rate and wait } 3 \\
\text { minutes }\end{array}$ \\
\hline Sample input & $\sim 100 \mathrm{ml} / \mathrm{min}$ \\
\hline
\end{tabular}

\section{RESULTS}

Unleaded gasoline was used as the fuel for this set of experiments. After the engine coolant temperature and lubricating oil temperatures have settled steady state conditions at $85^{\circ} \mathrm{C}$ and $70{ }^{\circ} \mathrm{C}$, respectively, data started to collect. A sample chromatogram of engine operation of 7:1 compression ratio, $900 \mathrm{rpm}$ engine speed and $20 \mathrm{CA}$ advance ignition is given in Fig. 2. As seen from Fig. 2, there are many $\mathrm{HC}$ peaks exist in the mixture. These peaks are very clear and segregated. Hydrocarbon analysis period is cut off at GC time of 15 minutes for this study. Methane formation after spark plug ignited around the sample point is plotted in Fig. 3. As seen from the figure, after charge is ignited, methane formation starts with $0 \mathrm{ppm}$ level at the $340 \mathrm{CA}$ and reaches to more than $190 \mathrm{ppm}$ after $50 \mathrm{CA}$. This result reveals that the heavy $\mathrm{HC}$ components are cracking to light $\mathrm{HCs}$ during the flame period.

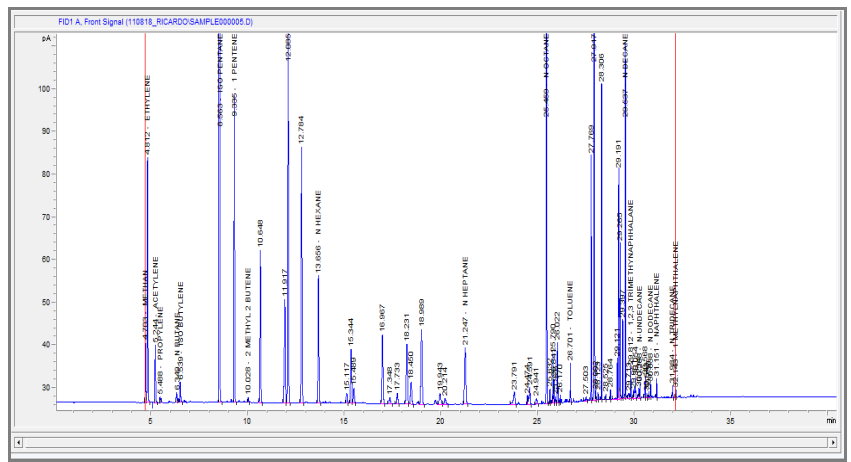

Fig. 2. Chromatogram of Ricardo engine operated on unleaded gasoline

Behavior of in-cylinder ethylene and acetylene formation is shown in Fig. 4. Formation trends of both components are similar to each other. However, due to simpler nature of acetylene, it reacts readily so less acetylene concentration is obtained end of combustion process. At the end of the flame period, HC component of ethylene reaches $823 \mathrm{ppm}$. This result shows that heavy $\mathrm{HC}$ components degraded to light $\mathrm{HC}$ components during the flame period in the engine cylinder.

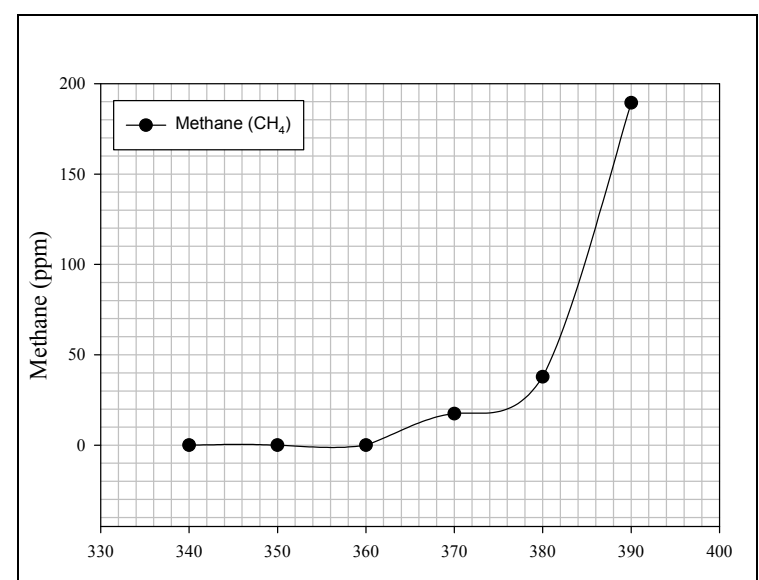

Fig. 3. Formation of methane in-cylinder during the combustion period with respect to $\mathrm{CA}$ at $\mathrm{r}=7: 1$ and $\mathrm{N}=900 \mathrm{rpm}$

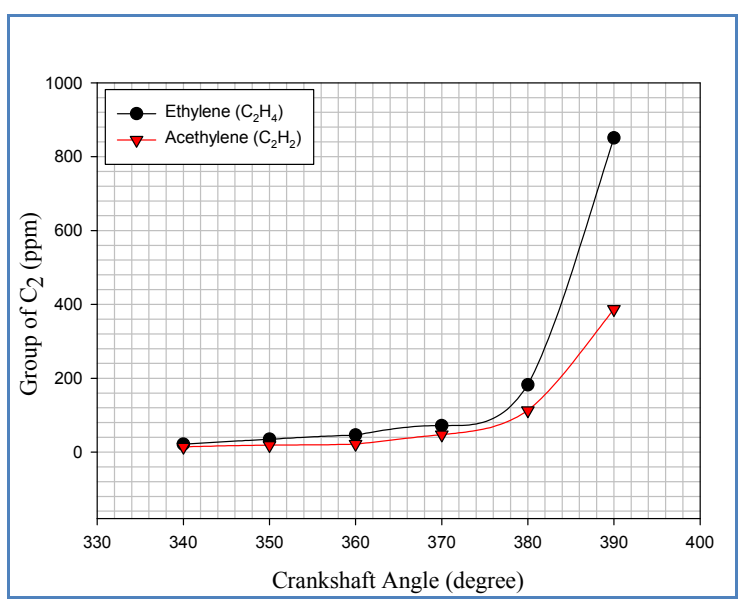

Fig. 4. Formation of group of $\mathrm{C}_{2}$ with respect to $\mathrm{CA}$ at $\mathrm{r}=7: 1$ and $\mathrm{N}=900$ rpm

For different engine speeds, iso-pentane concentration with respect to crank angle is demonstrated in Fig. 5. Before the ignition, iso-pentane concentrations are higher than 6000 ppm for all engine speeds considered. Due to combustion process proceeds, iso-pentane concentrations tend to decrease with respect to crank angle in the cylinder, for all engine speeds.

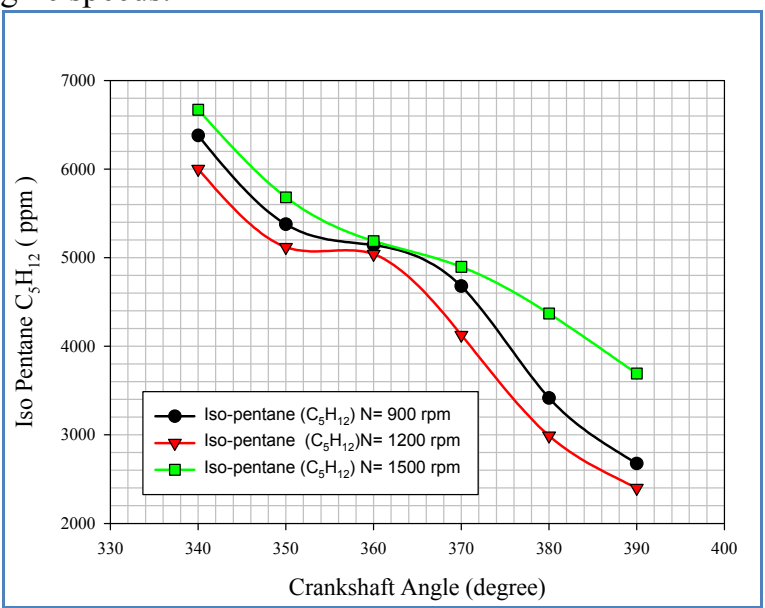

Fig. 5. Formation of $\mathrm{C}_{5} \mathrm{H}_{12}$ with respect to $\mathrm{CA}$ at $\mathrm{r}=7: 1$ and $\mathrm{N}=900,1200$, $1500 \mathrm{rpm}$ 
The variation of total amount of $\mathrm{HC}$ components, which include one to five carbon atoms per molecule (from $\mathrm{CH}_{4}$ to $\mathrm{C}_{5} \mathrm{H}_{12}$ ), with respect to crank angle is given in Fig. 6 .

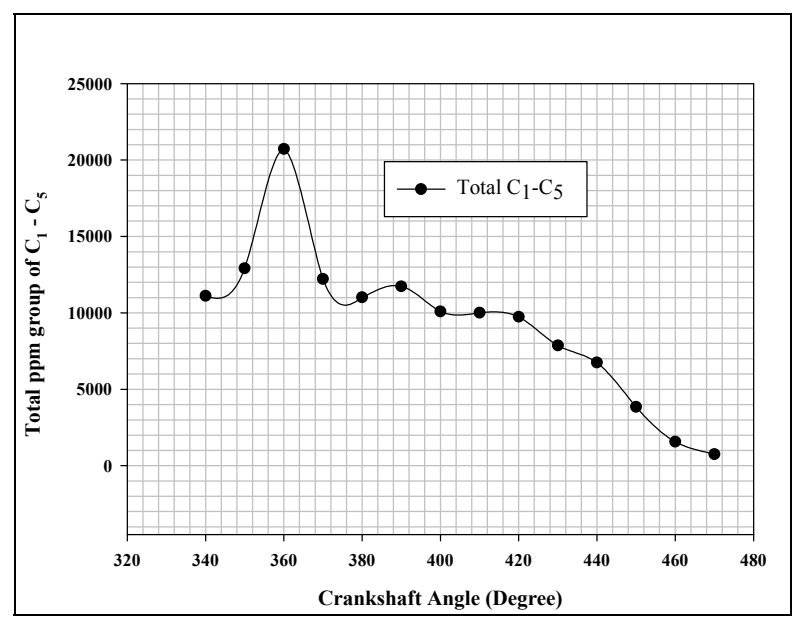

Fig. 6. Total amount of group of $\mathrm{C}_{1}-\mathrm{C}_{5} \mathrm{HCs}$ with respect to $\mathrm{CA}$ at $\mathrm{r}=7: 1$ and $\mathrm{N}=900 \mathrm{rpm}$.

When the spark ignition is occurred, HC level increases suddenly. This is an expectable result due to chemical degradation. At the end of the flame period, total $\mathrm{C}_{1}-\mathrm{C}_{5} \mathrm{HC}$ components decrease to $120 \mathrm{ppm}$ level. This result is consistent with the total amount tailpipe exhaust gas HC emissions, when the engine is operated at the same conditions.

\section{CONCLUSIONS}

Instantaneous $\mathrm{HC}$ component concentrations were analyzed simultaneously by using GC-FID technology. It is seen that the heavy $\mathrm{HC}$ components (as iso-pentane) tend to decrease during the flame period. On the other hand, light $\mathrm{HC}$ components (as ethylene, methane and acetylene) tend to rise during the expansion stroke. In addition, there is a peak value at the end of the combustion. This expected result shows that the chemical degradation occurs between the $\mathrm{HC}$ components during the combustion in the engine cylinder. This result should be taken into account for modeling of in-cylinder emission formation using CFD.

\section{REFERENCES}

[1] N. Ladommatos, "Cyclically resolved measurements of hydrocarbons in the cylinders on internal combustion engines, by means of a fast flame ionization detector," Journal of the Institute of Energy, vol. 65 (463), pp. 94-101, 1992.

[2] I. Shizuo and L. Tamotsu, "Experimental study on behavior of unburned hydrocarbons on combustion chamber wall of spark ignition engine," Transactions of Japan Society of Mechanical Engineers, vol. Part B 62 (596), pp. 1651-1658, 1996.

[3] A.C. Alkidas, "Combustion chamber crevices: the major source of engine out hydrocarbon emissions under fully warmed conditions," Progress in Energy and Combustion Science, vol. 25, pp. 253-273, 1999.

[4] H. Zuohua, Z. Ke, J. Deming, Z. Longbao, and P. Keyu, "Effect of fuel composition on hydrocarbon emissions in spark ignition engine," Journal of Combustion Science and Technology, vol. 3, no. 3, pp. 327-333, 1997.

[5] N. A. Henein, and M. K. Tagomori, "Cold start hydrocarbon emissions in port-injected gasoline engines," Progress in Energy and Combustion Science, vol. 25, pp. 563-593, 1999.

[6] N. Hadjconstantinou, K. Min, and J. B. Heywood, "Relation between flame propagation characteristics and hydrocarbon emissions under lean operating conditions in spark-ignition engines," in Symposium on Combustion 2, pp. 2637-2644, 1996.

[7] B. M. Broderick and I. S. Marnane, "A comparison of the C2-C9 hydrocarbon compositions of vehicle fuels and urban air in Dublin, Ireland," Atmospheric Environment, vol. 36, pp. 975-986, 2002.

[8] C. S. McEnally, D. M. Ciparu, and L. D. Pfefferle, "Experimental study fuel decomposition and hydrocarbon growth processes for practical fuel components: heptanes," Combustion and Flame, vol. 134, pp. 339-353, 2003.

[9] W. Yang, "The Chemistry Controlling Post Combustion Hydrocarbon Oxidation and Homogeneous Charge Compression Ignition," Ph.D. dissertation, Dept. Mechanical Eng., Drexel University, 2002.

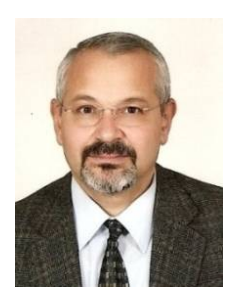

Nuri Yucel was graduated from Istanbul Technical University, Mechanical Engineering Department in 1979, in Turkey. After graduation he worked as a maintenance engineer in Turkish Petroleum Corporation for 2 and half year. He received his M.Sc. degree from Polytechnic Institute of New York in U.S.A, in 1984, and Ph.D. degree in Polytechnic University of New York in U.S.A, in 1988. Yucel is a member of Turkish Chamber of Mechanical Engineers and Turkish Society for Thermal Science and Technology. He is the editor-in-chief of Journal of Thermal Science and Technology. His major interest of study is numerical and experimental heat transfer, fluid flow, energy systems and internal combustion engines.

He worked as an assistant professor between 1988 and 1991 at Anadolu University in Eskisehir, Turkey. Later, he joined in Gazi University. He has been working as a full professor since 2000 . He has many conference and journal papers. 